AC 2009-966: A SIMPLE, YET EFFECTIVE, DEMONSTRATION OF POLYMERIC MECHANICAL BEHAVIOR

\title{
Lanny Griffin,
}

Jeffrey Swab, United States Military Academy 


\title{
A Simple, Yet Effective, Demonstration of Polymeric Mechanical Behavior
}

\begin{abstract}
Developing an appreciation for the mechanical behavior of polymers materials in a lecture mode can be challenging for students if they have not had the benefit of a laboratory experience. We have developed a simple demonstration of thermoplastic polymeric behavior using low-density polyethylene bags. The demonstration illustrates strengthening, rate effects, and directionality of strengthening and stiffness. Following the demonstration, students are better able to articulate the influence of structure, properties, processing, and performance as it applies to thermoplastic polymers.
\end{abstract}

\section{Introduction}

A firm grasp of the mechanical behavior of materials is necessary for engineers to select and employ materials in engineering design. Complex material behavior, such as that of polymers, can be a challenge to present to students in the introductory materials class. While linear elasticity and plasticity are relatively intuitive behaviors and are readily illustrated using springs or deformable metals, finding simple examples to demonstrate polymeric behavior is usually reserved for the lab. Our objective was to develop a simple and inexpensive way to demonstrate thermoplastic polymeric mechanical behavior (Fig 1) that can be used to enhance understanding and support the learning in the lecture and laboratory.

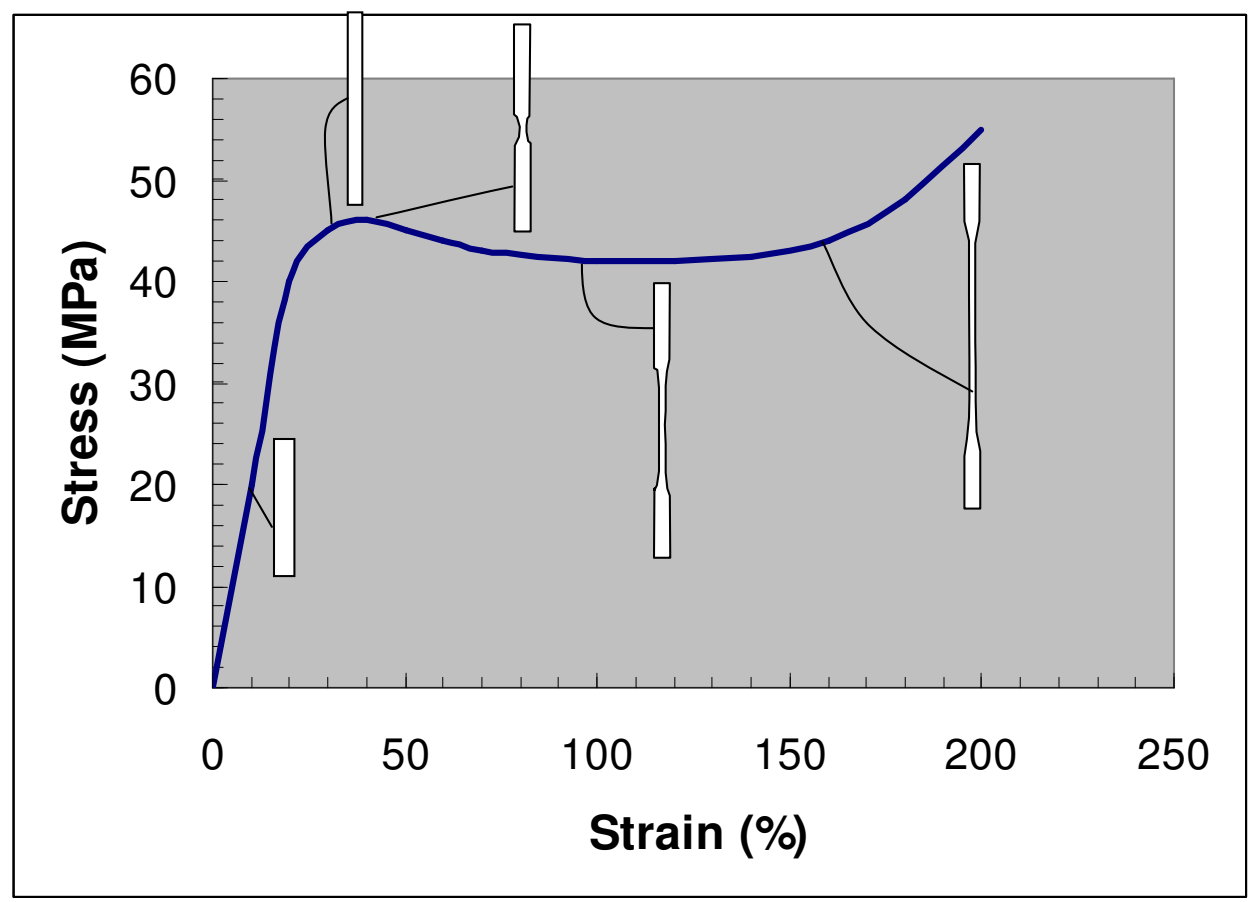

Figure 1: A typical pictorial representation of polymeric mechanical behavior. Similar depictions are found in most elementary materials textbooks. 


\section{Demonstration}

A basic tenant of materials engineering - our mantra - is that structure, processing, properties, and performance are all interrelated and interdependent. There are several layers that this demonstration can unravel and used to elucidate mechanical behavior and affects of processing in a semi-quantitative manner (full quantification can be left to laboratories). We typically use polyethylene grocery bags since they cost us nothing, but some garbage bags may work as well. As many samples as necessary for the class can be quickly generated using a straight edge, marker, and scissors. We will typically divide the samples into so-called longitudinal and transverse, depending on the orientation from which they were cut from the bag (Fig 2). It is helpful to label the samples with an L or T, depending on which orientation and the level of quantification desired.

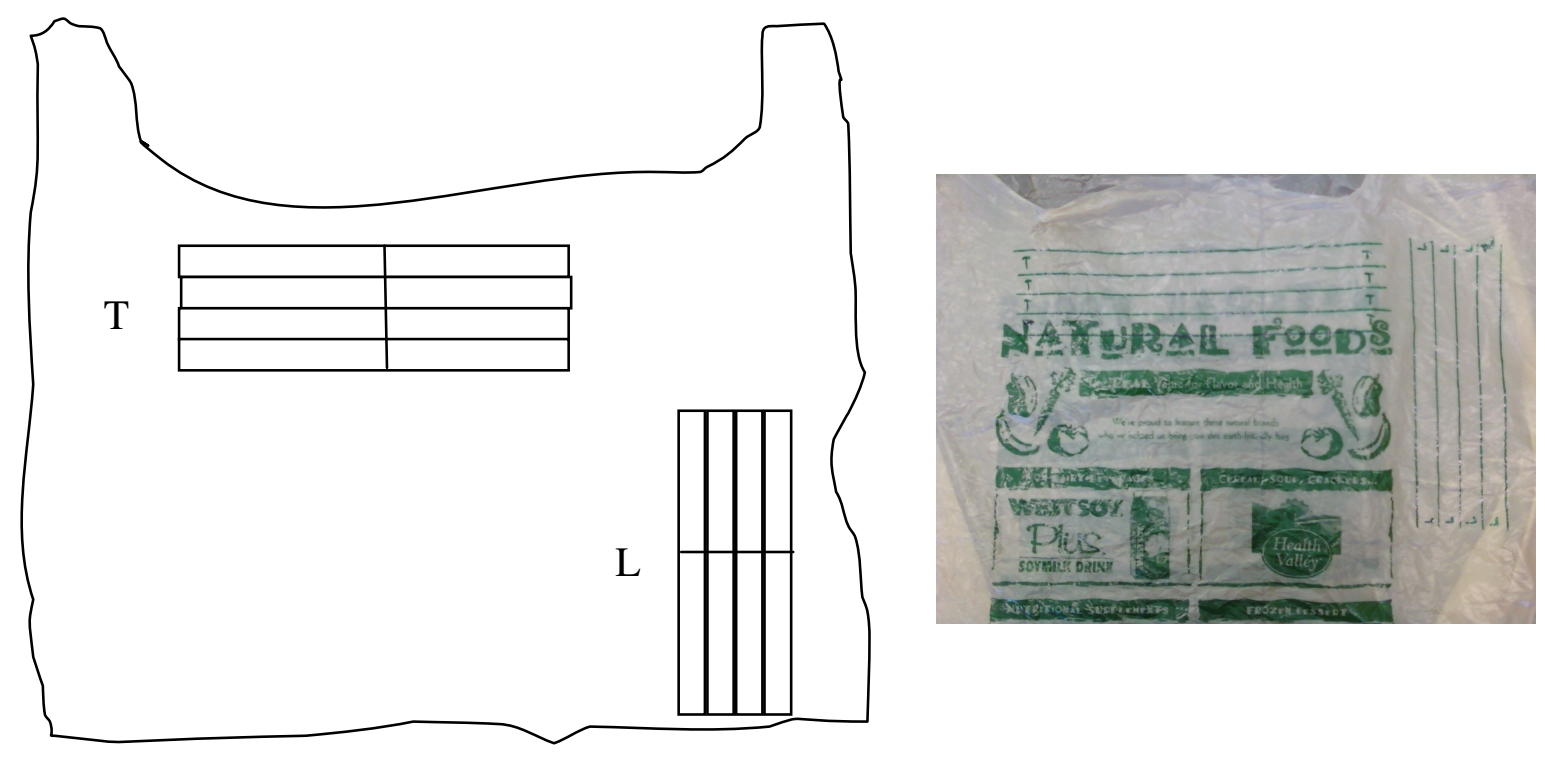

Figure 2: A description of the longitudinal and transverse orientations.

Depending on the degree of sophistication and objectives, it may be desirable to mark a gage length which can be used to estimate strain. Both initial length and width can be recorded for each sample. As an example for this study, we used ten longitudinal and transverse samples (Fig 3 , and Table 1).

Place as many samples as you wish each student to have on the desk before class, and instruct students not to touch the samples until instructed to do so (if nothing else, it will pique their curiosity). You may wish to put one $\mathrm{L}$ and one $\mathrm{T}$ on each desk depending on what your objectives are for the demonstration. 
Table 1: Initial measurements for the samples used in this study.

\begin{tabular}{|c|c|c|c|c|}
\hline & \multicolumn{2}{|c|}{ Transverse } & \multicolumn{2}{c|}{ Longitudinal } \\
\hline Sample & $\begin{array}{c}\text { Initial Gage } \\
\text { Length } \\
(\mathbf{c m})\end{array}$ & $\begin{array}{c}\text { Initial } \\
\text { Width } \\
(\mathbf{c m})\end{array}$ & $\begin{array}{c}\text { Initial Gage } \\
\text { Length } \\
(\mathbf{c m})\end{array}$ & $\begin{array}{c}\text { Initial } \\
\text { Width } \\
\text { (cm) }\end{array}$ \\
\hline 1 & 5.5 & 1.0 & 5.5 & 1.1 \\
\hline 2 & 5.5 & 1.0 & 5.5 & 1.1 \\
\hline 3 & 5.5 & 1.0 & 5.5 & 1.1 \\
\hline 4 & 5.5 & 1.0 & 5.5 & 1.1 \\
\hline 5 & 5.5 & 1.0 & 5.5 & 1.1 \\
\hline 6 & 5.5 & 1.0 & 5.5 & 1.1 \\
\hline 7 & 5.5 & 1.0 & 5.5 & 1.1 \\
\hline 8 & 5.5 & 1.0 & 5.5 & 1.1 \\
\hline 9 & 5.5 & 1.0 & 5.5 & 1.1 \\
\hline 10 & 5.5 & 1.0 & 5.5 & 1.1 \\
\hline
\end{tabular}

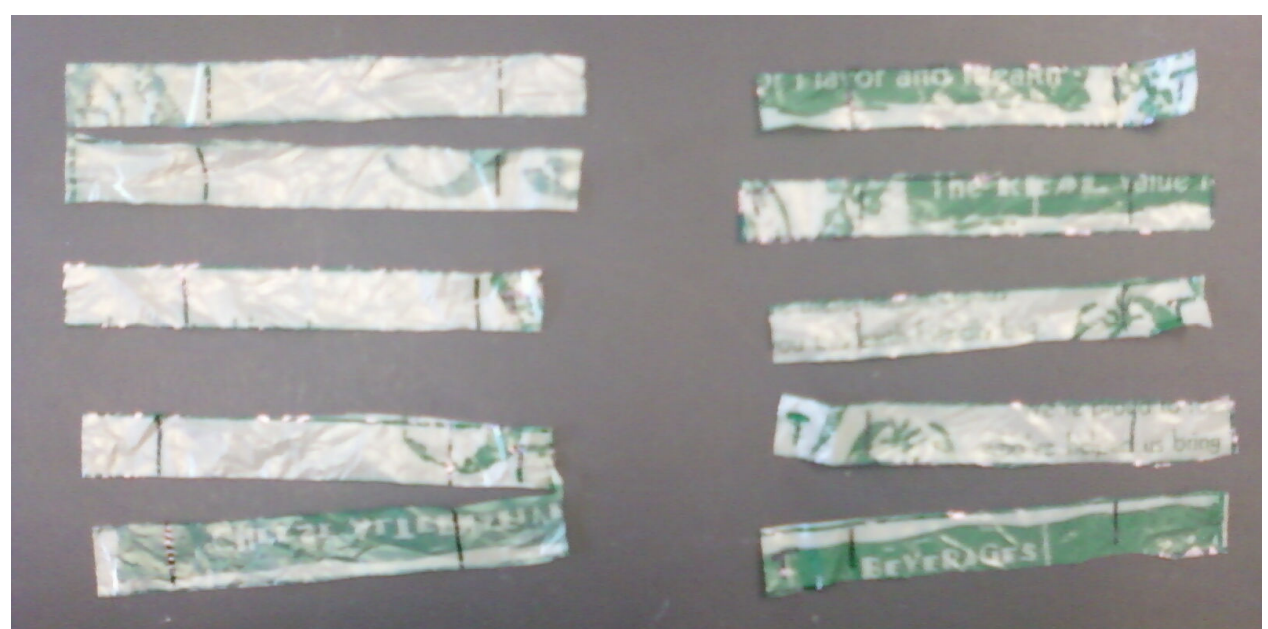

Figure 3: Typical samples marked with a gage length.

The demonstration begins by a basic explanation of the mechanical behavior (Fig 1). Afterwards, ask them to grasp the sample in the grip section firmly between their thumb and index finger, and then with a slow and steady application of tensile force, they are to attempt to extend the sample as far as they can. This portion of the demonstration can also be a contest to see who can extend their sample the farthest. We have always found that the transverse sample exhibit the behavior shown in figure 1 (more classic necking and extension) whereas the longitudinal samples have much less deformation and necking (Figure 4, Table 2). 


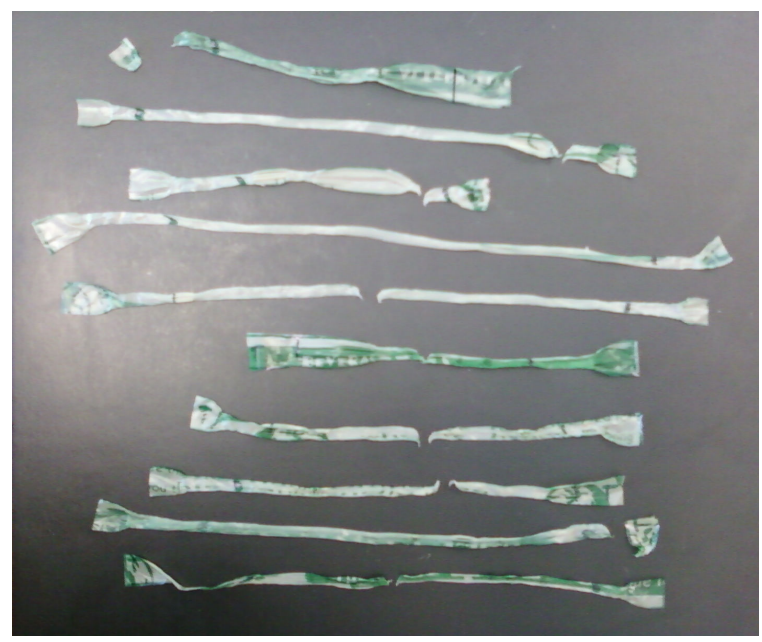

(a)

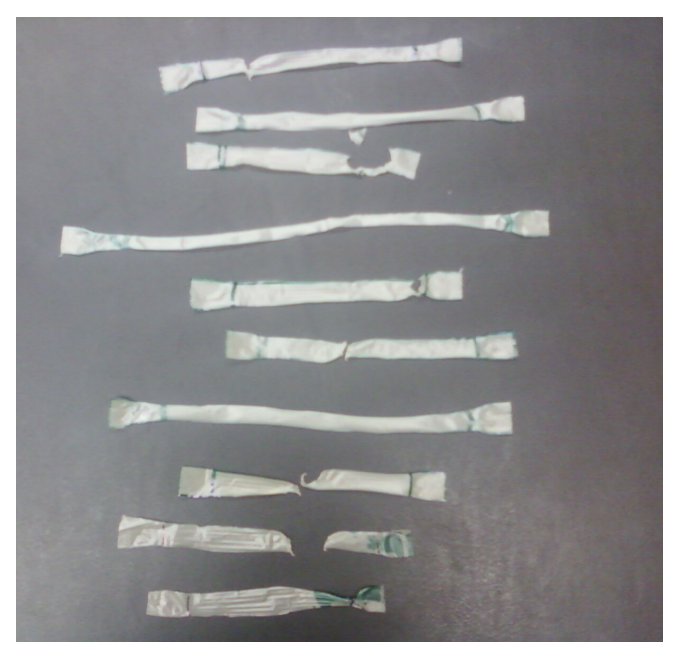

(b)

Figure 4: Sample appearance after deformation for (a) Transverse specimens, (b) Longitudinal specimens.

Table 2: Results from the demonstration $(\mathrm{N}=10)$. The superscripts a and b indicate statistically significant differences $(\mathrm{p}=0.05$ and $\mathrm{p}<0.0001$, respectively).

\begin{tabular}{|c|c|c|c|c|}
\hline & \multicolumn{2}{|c|}{ Transverse } & \multicolumn{2}{|c|}{ Longitudinal } \\
\hline Sample & $\begin{array}{c}\text { Longitudinal } \\
\text { Strain }(\%)\end{array}$ & $\begin{array}{l}\text { Transverse } \\
\text { Strain (\%) }\end{array}$ & $\begin{array}{c}\text { Longitudinal } \\
\text { Strain }(\%)\end{array}$ & $\begin{array}{l}\text { Transverse } \\
\text { Strain (\%) }\end{array}$ \\
\hline 1 & 172.7 & -50.0 & 45.5 & -1.0 \\
\hline 2 & 154.5 & -60.0 & 145.5 & -20.8 \\
\hline 3 & 136.4 & -50.0 & 72.7 & -10.9 \\
\hline 4 & 109.1 & -50.0 & 63.6 & -1.0 \\
\hline 5 & 72.7 & -50.0 & 227.3 & -50.5 \\
\hline 6 & 209.1 & -60.0 & 9.1 & -1.0 \\
\hline 7 & 245.5 & -60.0 & 100.0 & -20.8 \\
\hline 8 & 45.5 & -50.0 & 72.7 & -10.9 \\
\hline 9 & 190.9 & -60.0 & 36.4 & -9.9 \\
\hline 10 & 81.8 & -50.0 & 45.5 & -1.0 \\
\hline Average & ${ }^{\mathrm{a}} 141.8$ & ${ }^{b}-54.0$ & ${ }^{\mathrm{a}} 81.8$ & ${ }^{b}-12.8$ \\
\hline St Dev & 64.6 & 5.2 & 63.3 & 15.4 \\
\hline
\end{tabular}

We performed an ANOVA using longitudinal and transverse strains as the dependent variable and orientation (L or T) as the independent variable (Minitab V 15.1, Minitab Inc, State College, PA). We found that longitudinal samples have significantly greater longitudinal strains $(\mathrm{p}=0.05)$ and significantly greater transverse strains $(\mathrm{p}<0.0001)$. At this point, the explanations may begin. It is always desirable to relate properties to microstructure, and so a schematic representation is helpful which illustrates the effects of mechanical stress on the polymeric chains in the amorphous regions which are elongated in the direction of loading, resulting in higher strength (Fig 5). Most elementary materials textbooks include similar figures which can be drawn upon to explain the strengthening phenomenon ${ }^{1-3}$. Directionality may also be related to processing of the bag (processing affects structure affects performance). For example, the bags 
are often processed by blowing and pulling onto rollers in the longitudinal direction which again is illustrated in Fig 5. The directionality results from both directional solidification and mechanical stress in the longitudinal direction. Also, grocery bags may be heavily loaded in service, which also affects directionality since the bags are primarily loaded in the longitudinal direction. Some students may observe that there is banding that occurs in the neck of the transverse samples, whereas there is none in the longitudinal samples. Overall, there are many possible points that may be addressed, including the rate at which loading occurs which will have an affect on how much deformation will occur.
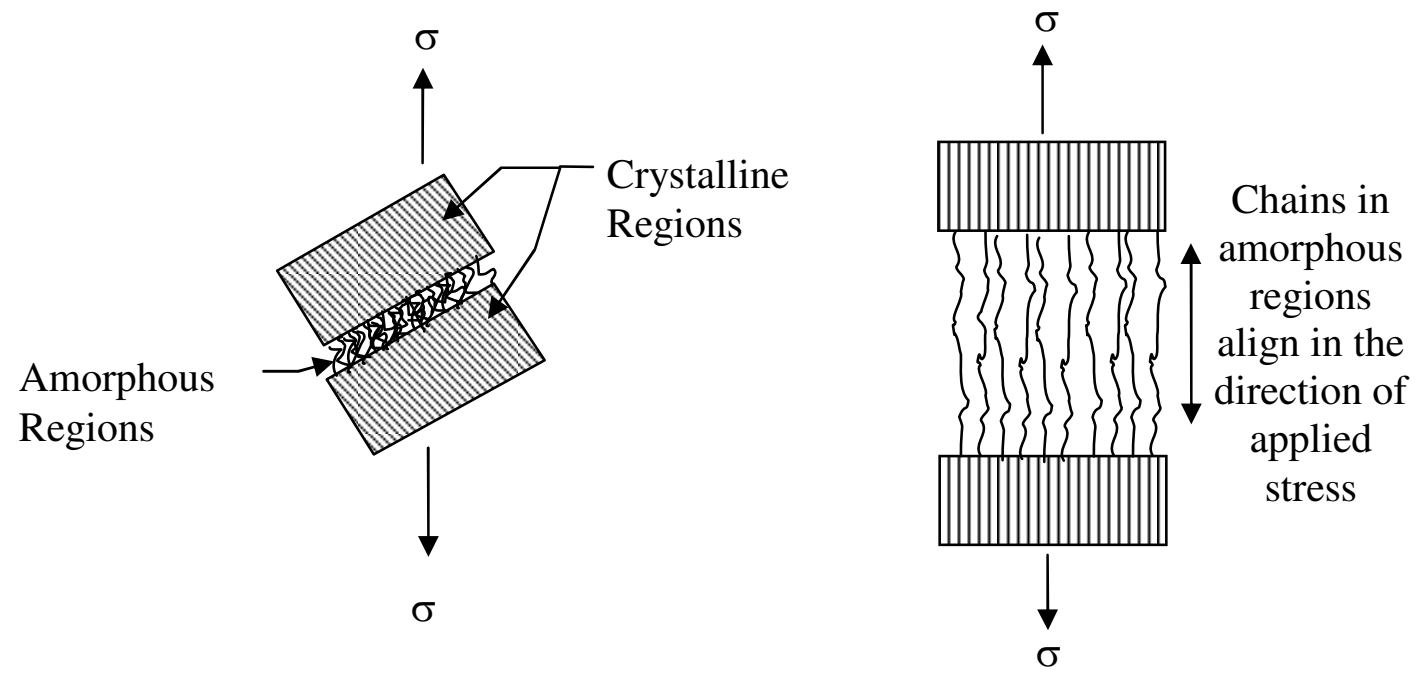

Figure 5: Depiction of microstructural changes that result from mechanically loading thermoplastic polymers that leads to strengthening.

We also have found that the directionality in the longitudinal and transverse directions can be eliminated if the samples are pre-loaded. The process effectively strengthens the polymer uniformly in both directions. In this case, begin with samples are at least $2.5 \mathrm{~cm}$ in width and 8 $\mathrm{cm}$ in length cut from both longitudinal and transverse directions (Fig 6). 


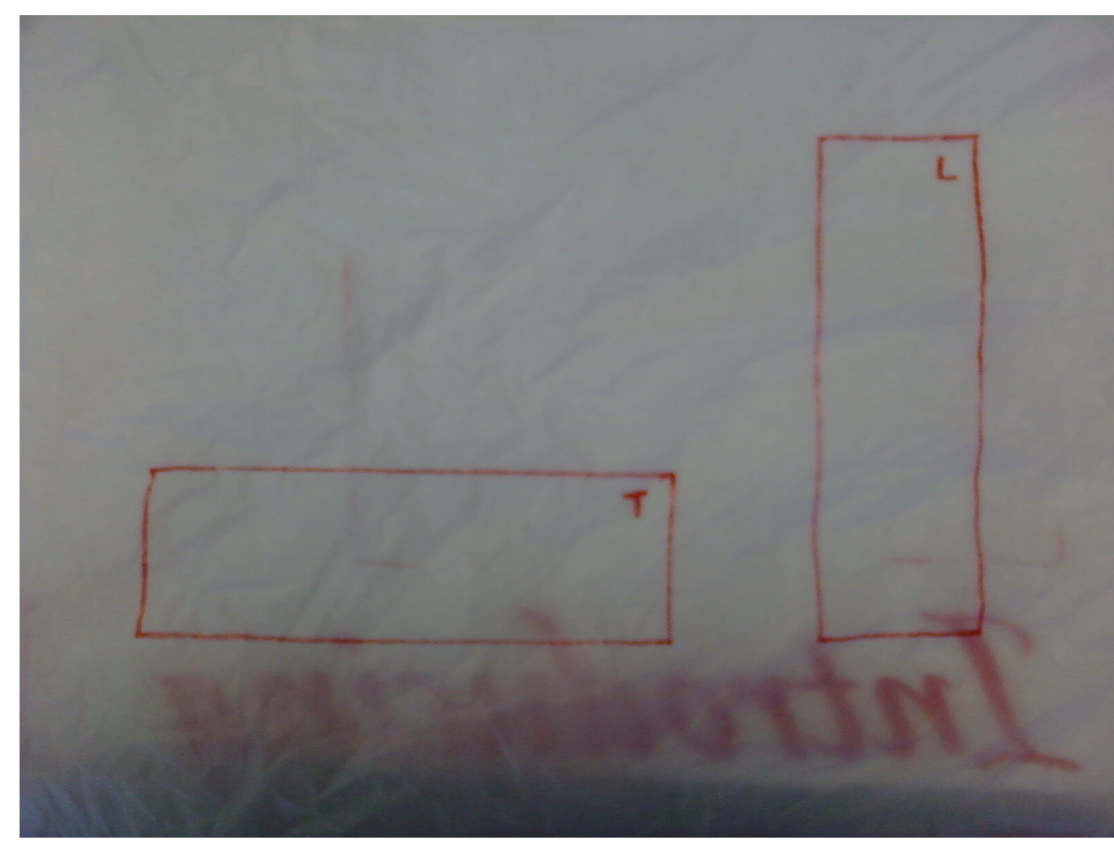

Figure 6: An example of wider samples for strengthening demonstration.

To pre-load the samples, grasp the ends and extend the specimens enough to create samples of similar size to the first experiment (some trimming will be required). There is some amount of "feel" necessary but the idea is to provide sufficient mechanical strengthening to remove the asreceived effects (Fig 7). The newly strengthened samples can then be cut to the same size as the initial demonstration and the procedure repeated. The resulting samples exhibit more isotropy in terms of strength - particularly when the results are compared to those in the first experiment (Fig 8).

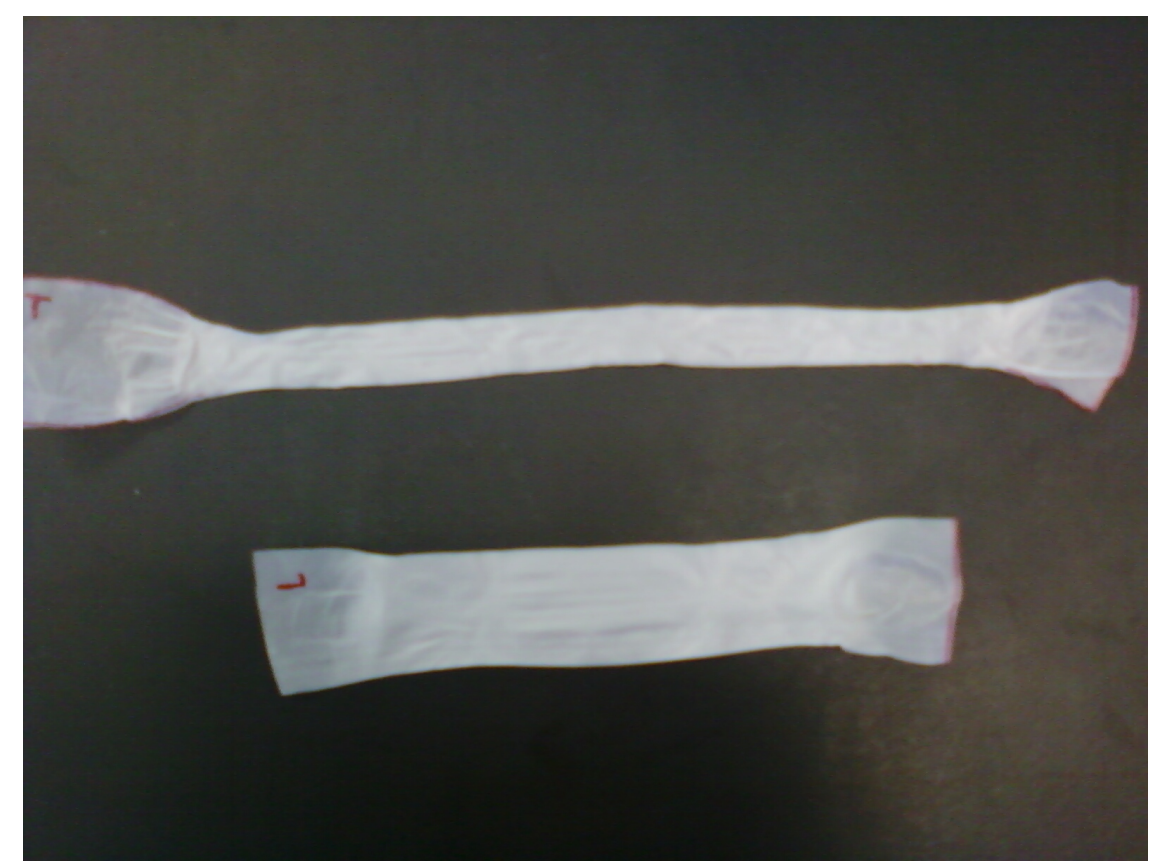

Figure 7: Pre-loaded samples that can be used to demonstrate the effects of directional strengthening. 
This portion of the demonstration clearly shows the effects of processing - in this case mechanical processing - on the performance of a polymer. These effects can be related to structure by the instructor in detail that is appropriate to the level of the class.

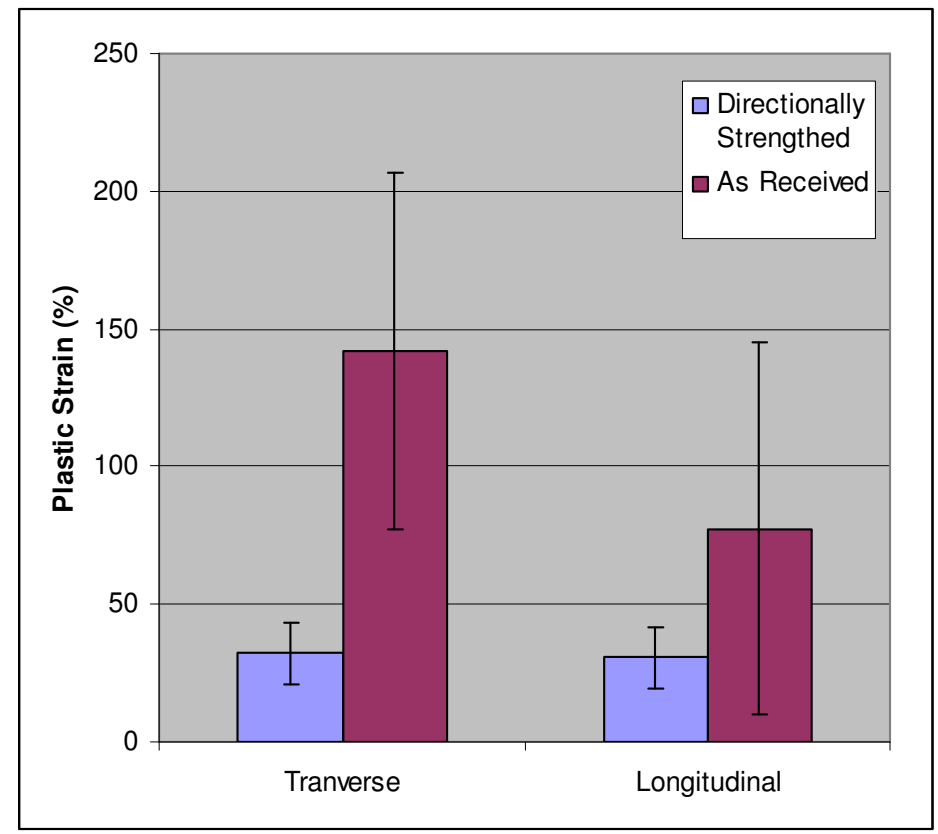

Figure 8: A comparison of directionally strengthened polymers to the as-received condition.

\section{Conclusions}

Our objective was to develop a simple and inexpensive way to demonstrate thermoplastic polymeric mechanical behavior that can be used to enhance understanding and support the learning in the lecture and laboratory. This demonstration has been used at two different engineering colleges and has supported enhanced learning. The demonstration is fun for students and provides numerous opportunities to explain and reinforce the inter-relationships of structure, processing, properties, and performance - particularly as it applies to polymers.

\section{Bibliography}

1. Callister, WD. (2006) Materials Engineering: An Introduction ( $7^{\text {th }}$ Ed). John Wiley and Sons, New York, NY.

2. Smith, WF and Hashemi, J. (2006) Foundations of Materials Science and Engineering ( ${ }^{\text {th }}$ Ed), McGraw Hill, New York, NY.

3. Murray, GT., White, CV, and Weise, W. (2007) Introduction to Engineering Materials. CRC Press, Boca Raton, FL. 